(REVIEW ARTICLE)

\title{
Recently investigated polymeric natural gums and mucilages for various drug delivery system
}

\author{
Mishra Manoj Kumar 1, ${ }^{*}$, Singh Abhishek ${ }^{1}$, Patel Amit Kumar ${ }^{2}$, Srivastava Rajat ${ }^{2}$ and Kushwaha Krishna ${ }^{3}$ \\ ${ }^{1}$ Shambhunath Institute of Pharmacy, Jhalwa, Prayagraj, Uttar Pradesh-211012, India. \\ ${ }^{2}$ ARK College of Pharmacy, Sarai Akkil, Kaushambi, Uttar Pradesh-212216, India. \\ ${ }^{3}$ Department of Pharmacy, Ashoka Institute of Technology and Management, Varanasi, Uttar Pradesh-221007, India.
}

Publication history: Received on 30 March 2020; revised on 06 April 2020; accepted on 07April 2020

Article DOI: https://doi.org/10.30574/wjarr.2020.6.1.84

\begin{abstract}
The use of natural excipients to deliver the bioactive agents has been hampered by the synthetic materials. However advantages offered by these natural excipients are their being non-toxic, less expensive and freely available. The performance of the excipients partly determines the quality of the medicines. The traditional concept of the excipients as any component other than the active substance has undergone a substantial evolution from an inert and cheap vehicle to an essential constituent of the formulation. Gums are widely used natural excipients for conventional and novel dosage forms. With the increasing interest in polymers of natural origin, the pharmaceutical world has compliance to use most of them in the formulations. Since plant polysaccharides comply with many requirements expected of pharmaceutical excipients such as non-toxicity, stability, availability and renewability they are extensively investigated for use in the development of solid oral dosage forms. Furthermore, polysaccharides with varying physicochemical properties can be extracted from plants at relatively low cost and can be chemically modified to suit specific needs. Excipients are any component other than the active substance(s) intentionally added to formulation of a dosage form. This article gives an overview of herbal excipients which are used in conventional dosage forms as well as novel drug delivery systems.
\end{abstract}

Keywords: Natural gum; Pharmaceutical excipient; NDDS; Polysaccharide

\section{Introduction}

Excipients are primarily used as diluents, binders, disintegrants, adhesives, glidants and sweeteners in conventional dosage forms like tablets and capsules[1]. In recent years, polymers those are derived from plant origin have evoked tremendous interest because of their diverse

pharmaceutical applications such as diluent, binder, disintegrant in tablets, thickeners in oral liquids, protective colloids in suspensions, gelling agents in gels, and bases in suppository. As the establishment of toxicity and approval from regulatory authorities poses a problem with synthetic excipients, of late more interest is being shown by researchers in herbal excipients. The drawback posed by heavy metal contamination often associated with herbal excipients is superseded by their lack of toxicity, easy availability, and economic considerations in pharmaceutical industry as compared to their synthetic counterparts. Present day consumers look for natural ingredients in food, drugs, and cosmetics as they believe that anything natural will be more safe and devoid of side effects. They have also been found useful in formulating immediate and sustained-release preparation. Of increasing importance is the fact that plant resources are renewable and if cultivated or harvested in a sustainable manner, they can provide a constant supply of raw material India, because of its geographical and environmental position, has traditionally been a good source for such products among the Asian countries. The specific application of plant-derived polymers in pharmaceutical formulations include their use in the manufacture of solid monolithic matrix systems, implants, films, beads,

\footnotetext{
* Corresponding author: Mishra Manoj Kumar
} 
microparticles, nanoparticles, inhalable and injectable systems as well as viscous liquid formulations. Polymers are often utilised in the design of novel drug delivery systems such as those that target delivery of the drug to a specific region in the gastrointestinal tract or in response to external stimuli to release the drug.

The traditional view that excipients are inert and do not exert any therapeutic or biological action or modify the biological action of the drug substance has changed and it is now recognized that excipients can potentially influence the rate and/or extent of absorption of a drug. As herbal excipients are non toxic and compatible, they have a major role to play in pharmaceutical formulation. Hence, this paper is an attempt to review herbal excipients used in NDDS. Gums are produced by members of a large number of families but commercial exploitation is restricted to a few species of Leguminosae, Sterculiaceae and Combretaceae (Table 2), there specific use in pharma industries in various formulations (Table 3) and some recently investigated natural gums and mucilages (Table 1).

Table 1 Some recently investigated natural gums and mucilage

\begin{tabular}{|c|c|c|c|c|}
\hline Sl. No. & Common name & Botanical name & Family & Pharmaceutical applications \\
\hline & $\begin{array}{l}\text { Abelmoschus } \\
\text { Gum } \\
\text { (Orka gum) }\end{array}$ & $\begin{array}{l}\text { Abelmoschus } \\
\text { esculentus }\end{array}$ & Malvaceae & $\begin{array}{l}\text { A suspending agent, a disintegrant in } \\
\text { low concentrations (4\%), poor floating } \\
\text { capacity in sustained release tablet but } \\
\text { with HPMC shows better results. Okra } \\
\text { polysaccharide as a microbially } \\
\text { triggered material for colon targeted } \\
\text { tablet formulation }\end{array}$ \\
\hline & Acacia & Acacia senegal & Combretaceae & $\begin{array}{l}\text { A suspending agent, emulsifying agent, } \\
\text { the binder in tablets, demulcent and } \\
\text { emollient in cosmetics Osmotic drug } \\
\text { delivery }\end{array}$ \\
\hline & Agar & Gelidium amansii & Gelidaceae & $\begin{array}{l}\text { Suspending agent, emulsifying agent, } \\
\text { gelling agent in suppositories, surgical } \\
\text { lubricant, tablet disintegrates, medium } \\
\text { for bacterial culture, laxative }\end{array}$ \\
\hline & Albizia Gum & Albizia zygia & Leguminoseae & $\begin{array}{l}\text { Tablet binder, coating materials in } \\
\text { compression-coated tablets }\end{array}$ \\
\hline & Almond gum & $\begin{array}{l}\text { Prunus } \\
\text { amygdalus }\end{array}$ & Rosaceae & $\begin{array}{l}\text { Emulsifying, thickening, suspending, } \\
\text { adhesive, glazing, and stabilizing } \\
\text { properties. Drug release increased }\end{array}$ \\
\hline & Aloe Mucilage & Aloe barbadensis & Liliaceae & Controlled release agent \\
\hline & Bhara gum & $\begin{array}{l}\text { Terminalia } \\
\text { bellerica Roxb }\end{array}$ & Combretaceae & Microencapsulation \\
\hline & Cactus mucilage & $\begin{array}{l}\text { Opuntia } \\
\text { ficusindica }\end{array}$ & - & Gelling agent in sustained drug delivery \\
\hline & Carragennan & Chondrus cryspus & Gigarginaceae & $\begin{array}{l}\text { Gelling agent, stabilizer in emulsions } \\
\text { and suspensions, in toothpaste, } \\
\text { demulcent and laxative }\end{array}$ \\
\hline & Cashew gum & $\begin{array}{l}\text { Anacardium } \\
\text { occidentale }\end{array}$ & Anacardiaceae & $\begin{array}{l}\text { Suspending agent, gelling property, } \\
\text { Controlled release agent }\end{array}$ \\
\hline & Cassia tora & Cassia tora Linn & Leguminosae & Binding agent \\
\hline & Chitosan & - & - & $\begin{array}{l}\text { Colon specific drug delivery, } \\
\text { microspheres, carrier for protein as } \\
\text { nanoparticles }\end{array}$ \\
\hline & $\begin{array}{l}\text { Fenugreek } \\
\text { Mucilage }\end{array}$ & $\begin{array}{l}\text { Trigonella } \\
\text { foenum-graceum }\end{array}$ & Leguminosae & better release retardant \\
\hline
\end{tabular}




\begin{tabular}{|c|c|c|c|}
\hline Gellan gum & $\begin{array}{l}\text { Pseudomonas } \\
\text { elodea }\end{array}$ & - & $\begin{array}{l}\text { Ophthalmic drug delivery, sustaining } \\
\text { agent, beads, hydrogels, floating in-situ } \\
\text { gelling, controlled release beads }\end{array}$ \\
\hline Guar gum & $\begin{array}{l}\text { Cyamompsis } \\
\text { tetraganolobus }\end{array}$ & Leguminosae & $\begin{array}{l}\text { Binder, disintegrant, thickening agent, } \\
\text { emulsifier, laxative, sustained release } \\
\text { agent }\end{array}$ \\
\hline Gum acacia & Acacia arabica & Leguminosae & $\begin{array}{l}\text { Suspending agent, emulsifying agent, } \\
\text { binder in tablets, demulcent and } \\
\text { emollient in cosmetics }\end{array}$ \\
\hline Gum ghatti & $\begin{array}{l}\text { Anogeissus } \\
\text { latifolia }\end{array}$ & Combretacea & Binder, emulsifier, suspending agent \\
\hline Gum tragacanth & $\begin{array}{l}\text { Astragalus } \\
\text { gummifer }\end{array}$ & Leguminosae & $\begin{array}{l}\text { Suspending agent, emulsifying agent, } \\
\text { demulcent, emollient in cosmetics and } \\
\text { sustained release agent }\end{array}$ \\
\hline Hakea & Hakea gibbosa & Proteaceae & $\begin{array}{l}\text { Sustained release and peptide } \\
\text { mucoadhesive for buccal delivery }\end{array}$ \\
\hline $\begin{array}{l}\text { Hibiscus } \\
\text { Mucilage }\end{array}$ & $\begin{array}{l}\text { Hibiscus } \\
\text { rosasinensis }\end{array}$ & Malvaceae & Sustained release \\
\hline Karaya gum & Sterculia urens & Sterculiaceae & $\begin{array}{l}\text { Suspending agent, emulsifying agent, } \\
\text { dental adhesive, sustaining agent in } \\
\text { tablets, bulk laxative }\end{array}$ \\
\hline Khaya gum & Khaya grandifolia & Meliaceae & Binding agent \\
\hline $\begin{array}{l}\text { Leucaena seed } \\
\text { gum }\end{array}$ & $\begin{array}{l}\text { Leucaena } \\
\text { leucocephata }\end{array}$ & & $\begin{array}{l}\text { Emulsifying agent, suspending agent, } \\
\text { binder in tablets, disintegrating agent in } \\
\text { tablets }\end{array}$ \\
\hline $\begin{array}{l}\text { Locust Bean Gum } \\
\text { (Carob gum) }\end{array}$ & Ceratonia siliqua & Leguminosae & Controlled release agent \\
\hline $\begin{array}{l}\text { Moringa } \\
\text { oleifera Gum }\end{array}$ & Moringa oleifera & Moringaceae & $\begin{array}{l}\text { The gelling property, Binding agent, } \\
\text { Controlled release agent }\end{array}$ \\
\hline Neem Gum & $\begin{array}{l}\text { Azadirachta } \\
\text { indica }\end{array}$ & Meliaceae & Controlled release agent \\
\hline Sodium alginate & $\begin{array}{l}\text { Macrocytis } \\
\text { pyrifera }\end{array}$ & Lessoniaceae & $\begin{array}{l}\text { Suspending agent, gelation for dental } \\
\text { films, stabilizer, sustained release } \\
\text { agent, tablet coating }\end{array}$ \\
\hline $\begin{array}{l}\text { Tamarind Seed } \\
\text { Polysaccharide }\end{array}$ & $\begin{array}{l}\text { Tamarindus } \\
\text { indica }\end{array}$ & Fabaceae & $\begin{array}{l}\text { Microspheres preparation (size range of } \\
230-460 \mu \mathrm{m} \text { ). In another study } \\
\text { Diclofenac sodium matrix tablets } \\
\text { containing TSP }\end{array}$ \\
\hline Xanthan gum & $\begin{array}{l}\text { Xanthomonas } \\
\text { lempestris }\end{array}$ & & $\begin{array}{l}\text { Suspending agent, emulsifier, stabilizer } \\
\text { in toothpaste and ointments, sustained } \\
\text { release agent }\end{array}$ \\
\hline
\end{tabular}


Table 2 List of few plants, which are commercially used gums with their product names

\begin{tabular}{llll}
\hline Sl. No. & Name of the source & Family & Exudate/Product \\
\hline 1 & A. senegal (L.) Willd. & Leguminosae & Gum arabic \\
2 & Acacia seyal Del. & Leguminosae & Gum arabic \\
3 & Anogiessuslatifolia Wall. & Combretaceae & Gum ghatti \\
4 & Astragalus gummifer & Leguminosae & Gum tragacanth \\
5 & Astragalus microcephalus Willd. & Leguminosae & Gum tragacanth \\
6 & Azadirachta indica A. Juss. & Meliaceae & Neem gum \\
7 & Cochlospermum gossypium L. & Cochlospermaceae & Gum karaya Lannea \\
8 & Lannea coromandelica & Anacardiaceae & Joel or Jingan gum \\
9 & Sterculia urens Roxb. & Sterculiaceae & Gum karaya \\
\hline
\end{tabular}

Table 3 Application of some gums in various novel drug delivery systems

\begin{tabular}{|c|c|c|c|}
\hline Sl. No. & Common Name & Novel Drug Delivery System & Drug \\
\hline & Acacia & Osmotic drug delivery & Water-insoluble Naproxen \\
\hline & Bhara gum & Microencapsulation & Famotidine \\
\hline & Cordia gum & $\begin{array}{l}\text { Novel oral sustained release matrix } \\
\text { forming agent in tablets. Suspension }\end{array}$ & Diclofenac sodium, Paracetamol \\
\hline & Guar gum & $\begin{array}{l}\text { Colon targeted drug delivery, Cross-linked } \\
\text { microspheres }\end{array}$ & $\begin{array}{l}\text { Albendazole, } \\
\text { Methotrexate }\end{array}$ \\
\hline & Gellan gums & $\begin{array}{l}\text { Ophthalmic drug delivery, Beads, Floating } \\
\text { in-situ gelling }\end{array}$ & Timolol, Propranolol, Amoxicillin \\
\hline & Karaya gums & Mucoadhesive and buccoadhesive & Nicotine \\
\hline & Locust bean gum & Controlled release agent & Nimodipine, Glipizide \\
\hline & Sodium alginate & Bioadhvesive microspheres & Gatifloxin, Metformin HCL \\
\hline & Tamarind gum & $\begin{array}{l}\text { Mucoadhesive drug delivery. Sustained } \\
\text { releases }\end{array}$ & $\begin{array}{l}\text { Diclofenac } \\
\text { Verapamil.HCL }\end{array}$ \\
\hline & Xanthan gum & Pellets. Controlled drug delivery system & Diclofenac sodium, Theophylline \\
\hline
\end{tabular}

\subsection{Classification based on source}

- Marine origin gums: agar, carrageenans, alginic acid and laminarin

- Plant origin: (i) shrubs/tree exudates: gum arabic, gum ghatti, gum karaya, gum tragacanth and khaya and albizia gums

- Seed gums: guar gum, locust bean gum, starch, amylose and cellulose

- Extracts: pectin and larch gum

- Tuber and roots: potato starch

- Animal origin: chitin and chitosan, chondroitin sulfate and hyaluronic acid

- Microbial origin (bacterial and fungal): xanthan, dextran, curdian, pullulan, zanflo, emulsan, Baker's yeast glycan, schizophyllan, lentinan, krestin and scleroglucan

- Oils: Caraway oil and Menthol. 


\subsection{Polysaccharides}

Natural polysaccharides are extensively used for the development of solid dosage forms. These polymers of monosaccharides (sugars) are inexpensive and available in a variety of structures with a variety of properties. They are highly stable, safe, non-toxic, and hydrophilic and gel forming in nature. Pectins, starch, guar gum, amylase and karaya gum are a few polysaccharides commonly used in dosage forms. Non-starch, linear polysaccharides remain intact in the physiological environment of the stomach and the small intestine, but are degraded by the bacterial inhabitants of the human colon which make them potentially useful in targeted delivery systems to the colon [2].

\section{Some recently investigated natural gum and mucilages used in various drug delivery systems}

\subsection{Tamarind seed gum}

This gum is obtained from insertion of endosperm of seeds of Tamarindus indica (family leguminosae) also known as known as Tamarind kernel powder. Though the seeds have lots of uses, it is a by-product of commercially used fruits of tamarind. The biodegradable polysaccharide present in gum called tamarind xyloglucan (Fig.1), responsible for high viscosity, adhesivity [3].

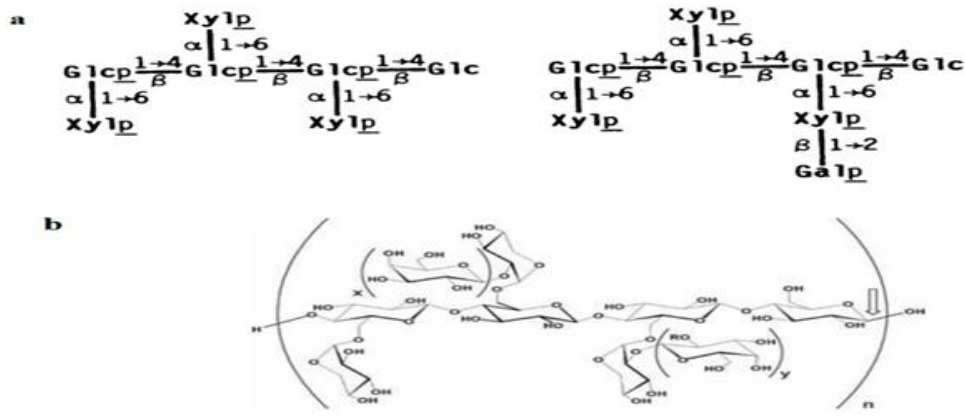

Figure 1 Chemical structure of Xyloglucan

The purified tamarind seed polysaccharide has partial chemical similarity with mucin MUC-1 and Epsialin. Capsules made from solid dispersion of Aceclofenac, Atorvastatin, Irbesartan with Tamarind Seed Polysaccharide (TSP) in ratio of 1: 3 as solubilizer; enhanced solubility and increased in dissolution characteristics as compared to pure drug without hampering the stability of formulation [4]. In vitro drug release study evaluated matrix tablet of ibuprofen using Tamarind Seed Polysaccharide reveals that degradation of polysaccharide take place in simulated colonic fluid having rat caecal content and about $81.7 \%$ drug released in colon. This concluded that tamarind seed polysaccharide useful for colonic drug delivery system [5].

\subsection{Locus bean gum}

Locus bean gum (Fig. 2) is produced from seeds of legumes of the plant Ceratonia siliqua Linn. (Family Fabaceae) get cultivated in mediterranean region.

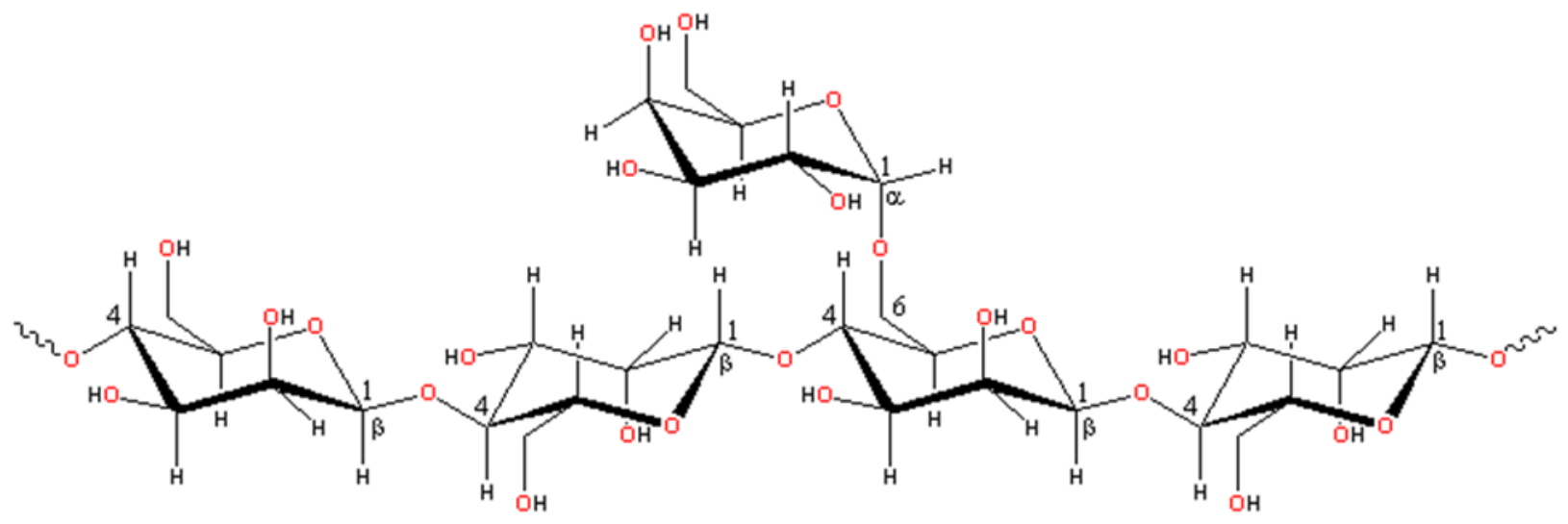

Figure 2 Chemical structure of Locust bean gum 
Penwest Pharmaceuticals Company developed TIMERx® tablet system, commercially available; using locust bean gum and xanthan gum exhibited both in vitro and in vivo controlled release profile [6]. Viscogum ${ }^{\mathrm{TM}}$ LBG is available in market.

\subsection{Okra mucilage}

Abelmoschus esculentus pods (family: Malvaceae) of flowering plant are called okra pods (Fig. 3) when soaked in water for sufficient time release the mucilage. Further to get amorphous mucilage alcohol is added.

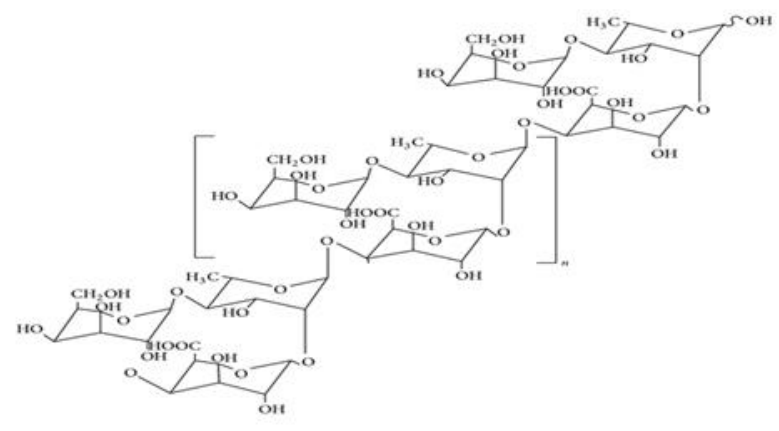

Figure 3 Chemical structure of Okra Mucilage

Okra mucilage as tablet binder in Diclofenac sodium matrix tablets had formulated; shown proper hardness and friability. The study revealed that increase in concentration of mucilage reduction in release of drug from matrix tablet and thus the mucilage shown excellent retarding effect on release of drug at very low concentration [7]. For sustain release of albendazole matrix tablet using okra mucilage shown $98.3 \%$ drug release at the end of $10 \mathrm{hr}$. when used $30 \%$ of total tablet weight.

\subsection{Fenugreek seed mucilage}

Fenugreek is Trigonella Foenum-graceum (family: Leguminosae), widely used as food and food additive composed of Trigonelline (Fig. 4). The mucilage from the seed coat is obtained after soaking the defatted powder of frenugreek seed with water. The amorphous powder of mucilage is tasteless, off-white in color, with slide acidic in nature.

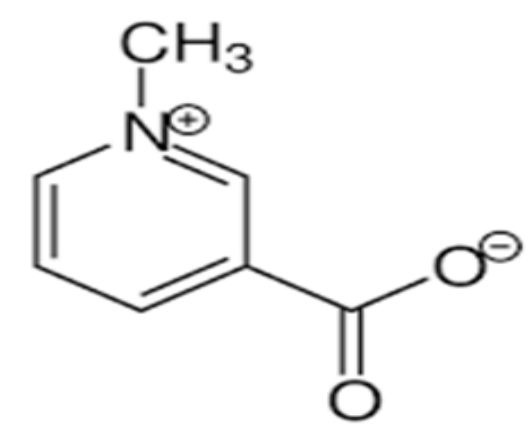

Figure 4 Chemical structure of Trigonelline

Fast dissolving tablet of metformin Hydrochloride disintegrated in 15 seconds and shown $100 \%$ drug release within 18 min. at $4 \%$ concentration of fenugreek mucilage indicated good disintegrant property [8]. Nasal delivery of Diazepam using fenugreek mucilage was developed shown good polymer property than HPMC, carbopol 934 with respect to mucoadhesive strength, gelling and drug release. The mucilage was also evaluated for super-disintegrating property of sildenafil citrate fast dissolving tablet [9].

\subsection{Mango peels pectin}

Mango peel, result of the mango composing of Mangiferin (Fig. 5) processing waste in food industry was found to be a good source for yielding 10-20\% good quality pectin. Pectin is a complex hetro-polysacharides which is a hydrophilic colloid. 


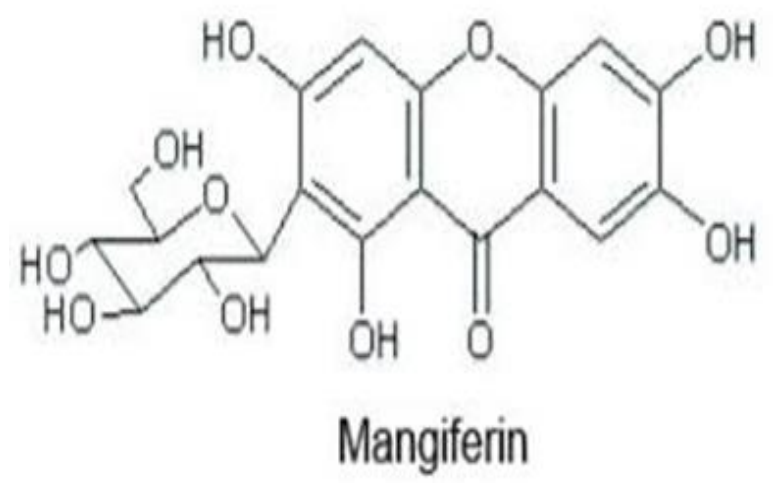

Figure 5 Chemical structure of Mangiferin

Study had been done to investigate that superdisintegrant property of mango peel pectin as it had shown comparatively lesser release of drug than synthetic superdisintegrant cannot be used alone as major disintegrant in formulation but due to its good solubility and higher swelling index, it may be used in the formulation of fast dispersible tablets [10].

\subsection{D-Limonene}

D-Limonene (Fig.6) is obtained as a by-product of the citrus juice industry. It is the major component of the oil extracted from the rinds of citrus fruits.

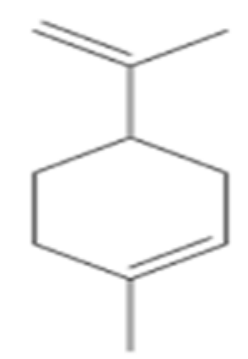

Figure 6 Chemical structure of D-limonene

A limonene-based transdermal therapeutic system (TTS) was prepared to study its ability to provide the desired steadystate plasma concentration of nicorandil in human volunteers [11].

\subsection{Gum Dabar}

This is consists of dammarane (Fig. 7) whitish to yellowish resinous material obtained from plant Shorea wiesneri (family: Dipterocarpaceae).

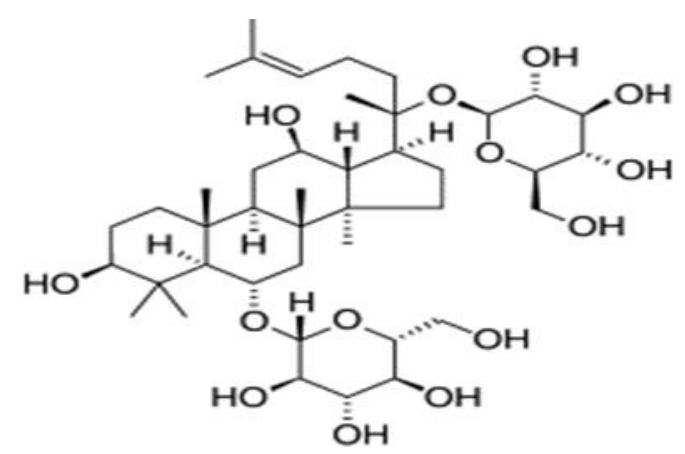

Figure 7 Chemical structure of Dammarane 
Microcapsules of ibuprofen and diltiazem hydrochloride prepared using gum damar investigated for sustained drug delivery. Microparticles were formulated by oil-in-water emulsion solvent evaporation method. In case of diltiazem $\mathrm{HCl}$ which water soluble drug micro particle were bigger and releasing drug rapidly as low level of encapsulation. While in case of slightly water soluble drug i. e. ibuprofen micro particles were small having good encapsulation and thus exhibited sustain drug delivery [12].

\subsection{Rosin}

Rosin (Fig. 8) is oleoresin, a natural polymer obtained from pine trees, sources being Pinus soxburghui, Pinus longifolium and Pinus toeda. Rosin is mainly consists of abietic and pimaric acids and has excellent film-forming properties [13].

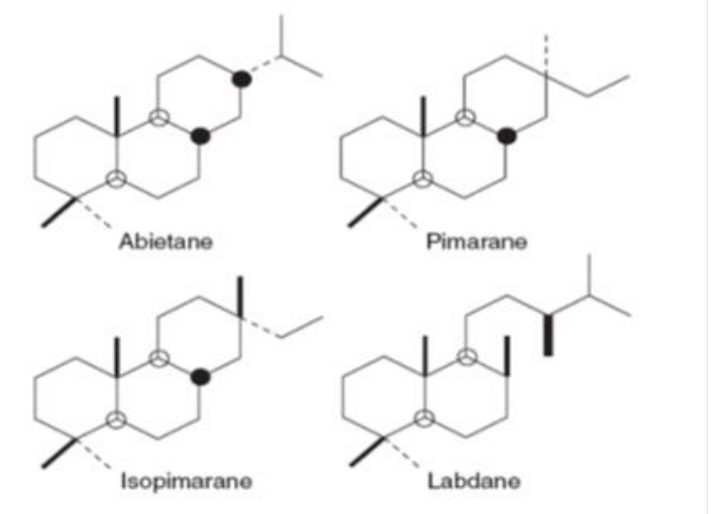

Figure 8 Chemical structure of resin of rosin

Polymerised rosin films containing hydrophobic plasticizers showed excellent potential as coating materials for the preparation of sustained release dosage forms [14].

\subsection{Albizia gum}

Albizia gum is obtained from the incised trunk of the tree Albizia zygia (Family Leguminosae). It consists of $\beta$-1-3-linked D galactose (Fig. 9) units with some B1-6-linked D-galactose units.

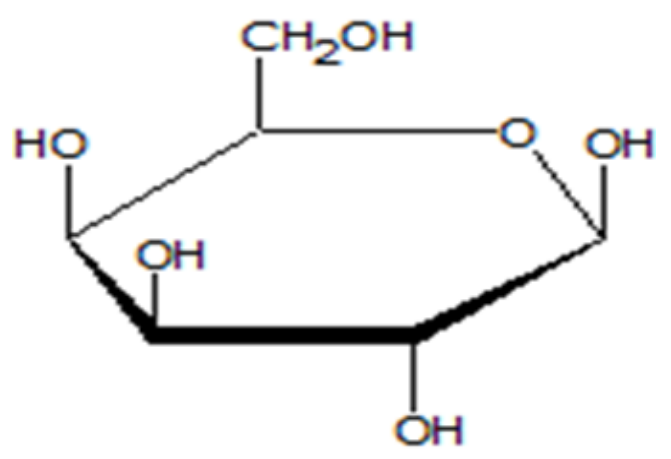

Figure 9 Chemical structure of galactose

Albizia gum has been investigated as a possible substitute for gum arabic as a natural emulsifier for food and pharmaceuticals. These gums were tried as coating materials in compression-coated tablets, which degraded, by the colonic microflora, thereby releasing the drug [15].

\subsection{Honey locust gum}

The gum consisting of D-glucuronic acid (Fig. 10) is obtained from the seeds of the plant Gleditsia triacanthos (family: Leguminosae). Seeds contain proteins, fats, carbohydrates, and fibres. 


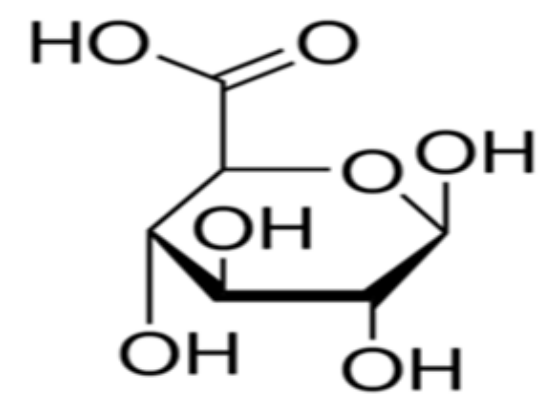

Figure 10 Chemical structure of D-glucuronic acid

Honey locust gum has been used to produce matrix tablets at different concentrations (5\% and $10 \%)$ by wet granulation method [16].

\subsection{Cashew gum}

Cashew gum is the exudate from the stem bark of Anacardium occidentale (family: Anacardiaceae). The gum contains galactose, arabinose, rhamnose, glucose, glucuronic acid, and other sugar residues, while hydrolysis of the gum yields D- and L-arabinose (Fig. 11), L-rhamnose, D-galactose, and glucuronic acid [17].<smiles>O=CC(O)C(O)C(O)CO</smiles>

D-Arabinose<smiles>O=CC(O)C(O)C(O)CO</smiles>

\section{L-Arabinose}

Figure 11 Chemical structure of D-and L-Arabinose

Studies were performed on cashew gum for its gelling property. The gels prepared with 5.0\% of mucilage were found to be ideal and comparable with a commercial preparation. The prepared gels did not produce any dermatological reactions. The gels were found to be stable with respect to viscosity, drug content, and physical appearance at all temperature conditions for 3 months. Cashew gum was also studied for its binding property. In this study binding property of cashew gum was compared with acacia. It was observed that the disintegration time of the tablet increased with increase in concentration of cashew gum and controlled release property wherein study showed that increase in the polymer ratio retarded the drug release to a greater extent.

\subsection{Neem gum}

Neem gum is obtained from the trees of Azadirachta indica (family: Meliaceae). Gum contains uronic acid (Fig. 12), mannose, glucosamine, arabinose, galactose, fucose, xylose, and glucose [18].

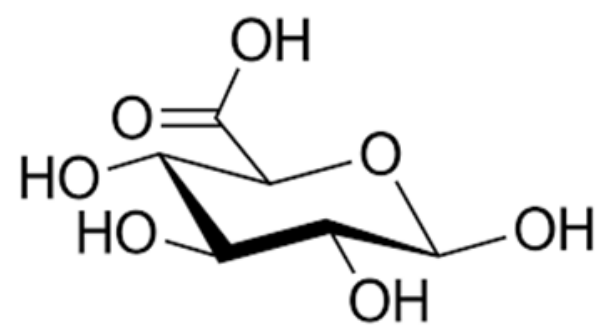

Figure 12 Chemical structure of Uronic acid 
Studies were performed on neem gum for its binding property and sustained release property. Results show that as the proportion of Azadirachta indica fruit mucilage increases, the overall time of release of the drug from the matrix tablet also increases.

\subsection{Aloe mucilage}

Aloe mucilage is obtained from the leaves of Aloe barbadensis (family: Liliaceae). It contains aloe-emodin (Fig. 13), arabinan, arabinorhamnogalactan, galactan, galactogalacturan, glucogalactomannan, galactoglucoarabinomannan and glucuronic acid containing polysaccharides [19].<smiles>O=C1c2cccc(O)c2C(=O)c2c(O)cc(CO)cc21</smiles>

Figure 13 Chemical structure of Aloe-emodin

A controlled delivery system of glibenclamide using aloe mucilage was studied. Various formulations of glibenclamide with Aloe barbadensis Miller leaves mucilage were prepared by direct compression technique. The formulated matrix tablets were found to have better uniformity of weight and drug content with low statistical deviation. The swelling behaviour and in vitro release rate characteristics were studied. The dissolution study proved that the dried Aloe barbadensis Miller leaves mucilage can be used as a matrix forming material for making controlled release glibenclamide matrix tablets [20].

\subsection{Moringa oleifera gum}

Gum is obtained from exudes of stem of Moringa oleifera (family: Moringaceae). The gum is a polyuronide constituting of L-arabinose, D-galactose, and glucuronic acid in the preparation of 10: 7: 2, rhamnose present in traces. Studies were performed on this gum for its gelling property. The gelling concentration of the gum was found to lie between 7 and $8.5 \% \mathrm{w} / \mathrm{v}$. The gels exhibited pseudoplastic flow and viscosity were found to be ideal for topical application binding property and release retardant property. Different batches of tablet were prepared and evaluated for drug release. It was observed that drug release increased with increasing proportions of the excipient and decreased proportion of the gum. Release mechanism was found to be Fickian [21]. Gum was also studied for its disintegrating property. Different batches of tablets were formulated varying them by quantity of the gum. It was observed that wetting time decreased with the increase in concentration of gum in formulation; thus disintegration time of tablet formulation prepared from gum was found lesser as compared to tablet formulation prepared from synthetic disintegrant like starch, sodium glycolate (SSG), and croscarmellose sodium (CCS) [22].

\subsection{Phoenix mucilage}

Phoenix mucilage is obtained from the dried fruit of Phoenix dactylifera (family: Palmaceae). Carbohydrates make up to $44-88 \%$ of the fruit which include $\beta$-Amyrin (Fig. 14) and reducing sugars such as fructose, sucrose, mannose, glucose, and maltose in addition to small amounts of polysaccharides such as pectin (0.5-3.9\%), starch, and cellulose.

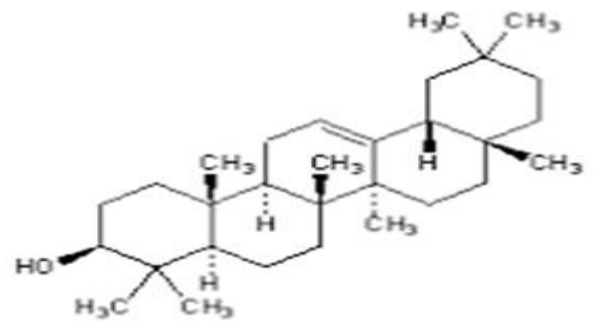

Figure 14 Chemical structure of $\beta$-Amyrin 
Binding properties of date palm mucilage were successfully evaluated. The tablets manufactured using phoenix mucilage was found to be less friable than tablets manufactured using acacia and tragacanth. As the concentration of the gum increased the binding ability improved, producing good uniformity in weight and hardness of the tablets [23].

\subsection{Cassia tora mucilage}

Cassia tora mucilage derived from the seeds of Cassia tora (family: Caesalpiniaceae). The primary chemical constituents of Cassia include $\alpha$-D-galactopyranose (Fig. 15), cinnamaldehyde, gum, tannins, mannitol, coumarins and essential oils (aldehydes, eugenol and pinene); it also contains sugars, resins, and mucilage among other constituents [24].

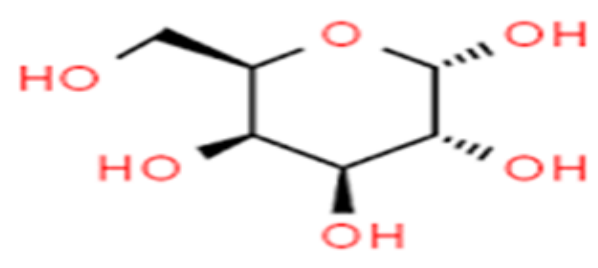

Figure 15 Chemical structure of $\alpha$-D-galactopyranose

Studies were performed on Cassia tora mucilage for its binding property. It was observed that increasing the concentration of mucilage increases hardness and decreases the disintegration time of the tablets which were formulated with different concentrations of cassia tora gum [25]. This mucilage was also evaluated for its suspending agent. The suspending ability of Cassia tora mucilage was compared with that of tragacanth, acacia, and gelatin. The suspending ability of all the materials was found to be in the order: Cassia tora > tragacanth gum > acacia gum. Gelatin results suggest that suspending action of the mucilage is due to high viscosity of the gum [26].

\subsection{Mimosa mucilage}

Gum is obtained from seeds of Mimosa pudica (family: Mimosaceae). Seed mucilage is composed of mimosine (Fig. 16), D-xylose and D-glucuronic acid. Mimosa seed mucilage hydrates and swells rapidly on coming in contact with water.

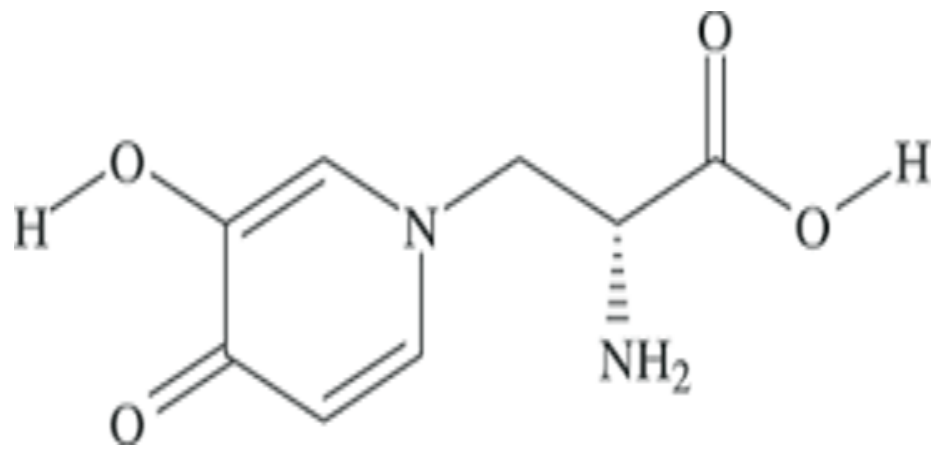

Figure 16 Chemical structure of mimosine

A controlled delivery system for diclofenac sodium using Mimosa seed mucilage was studied. In this study different batches of tablets were formulated and their drug releases were checked. It was observed that as the proportion of the Mimosa pudica seed mucilage increases, there is a decrease in release of drug, the mechanism of release being diffusion for tablets containing higher proportion of mucilage, and a combination of matrix erosion and diffusion for tablets containing smaller proportion of mucilage. Studies showed that as the proportion of the mucilage increased, there was a corresponding increase in increase in percent swelling and decrease in percent erosion of the tablets [27]. 


\subsection{Terminalia gum}

Terminalia gum exudates are from the incised trunk of the tree Terminalia randii (family: Combretaceae). A number of chemical constituents have been isolated from the plant extract that include chebulinic acid (Fig. 17), ellagic acid, 2,4chebulyl-D-glucopyranose, arjunglucoside I, arjungenin, chebulinic acid, gallic acid, ethyl gallate, punicalagin, terflavin A, terchebin, luteolin and tannic acid.

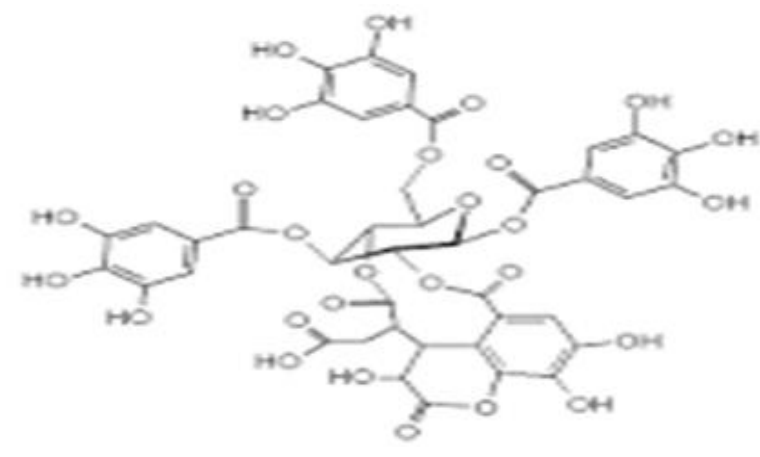

Figure 17 Chemical structure of chebulinic acid

Extracts of the stem and bark of Terminalia randii are used in the treatment of dysentery, diarrhea, hemorrhoids, and wounds. Gum exudates obtained from Terminalia randii have been evaluated as binding agent. The results showed that the crushing strength and crushing strength friability ratio increased with increase in polymer concentration while friability decreased [28].

\subsection{Ocimum mucilage}

Ocimum mucilage is obtained from the seeds of Ocimum americanum commonly called Ocimum canum (family: Lamiaceae). Mucilage contains xylose (Fig. 18), arabinose, rhamnose, and galacturonic acids.

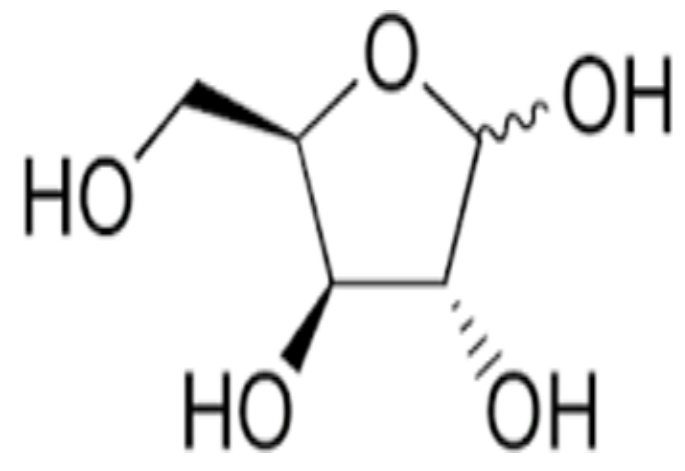

Figure 18 Chemical structure of xylose

The mucilage was found to have disintegrating property. The disintegration time for tablet formulations prepared using ocimum mucilage was less than tablets that were prepared by using starch as a disintegrant [29].

\subsection{Pectin}

Pectins are non-starch, linear polysaccharides extracted from the plant cell walls. They are predominantly linear polymers of mainly (1-4)-linked D-galacturonic acid (Fig. 19) residues interrupted by 1,2- linked L-rhamnose residues with a few hundred to about one thousand building blocks per molecule, corresponding to an average molecular weight of about 50, 000 to about $1,80,000$. 


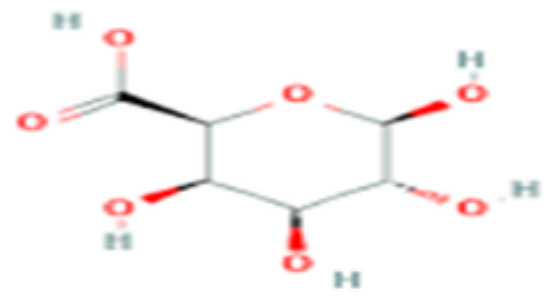

Figure 19 Chemical structure of D-galacturonic acid

Being soluble in water, pectin is not able to shield its drug load effectively during its passage through the stomach and small intestine. It was found that a coat of considerable thickness was required to protect the drug core in simulated in vivo conditions. Hence the focus was shifted to the development of less soluble derivatives of pectin which get degraded by the colonic microflora. Calcium salts of pectin reduced their solubility by forming an egg-box configuration. To overcome the drawback of high solubility of pectin, mixed films of pectin with ethyl cellulose were investigated as a coating material for colon-specific drug delivery. These films combined the colon specific degradation properties of pectin with the protective properties of the water insoluble polymer ethyl cellulose. .

Micro particulate polymeric delivery systems have been suggested as a possible approach to improve the low bioavailability characteristics shown by standard ophthalmic vehicles (collyria). In this context pectin microspheres of piroxicam were prepared by the spray drying technique. In vivo tests in rabbits with dispersions of piroxicam-loaded microspheres also indicated a significant improvement of piroxicam bioavailability in the aqueous humour (2.5-fold) when compared with commercial piroxicam eyedrops[30].

Calcium pectinate nanoparticles to deliver insulin were prepared as a potential colonic delivery system by ionotropic gelation[31]. In relation to the food industry, folic acid incorporated microcapsules were prepared using alginate and combinations of alginate and pectin polymers so as to improve stability of folic acid. Folic acid stability was evaluated with reference to encapsulation efficiency, gelling and hardening of capsules, capsular retention during drying and storage. The blended alginate and pectin polymer matrix increased the folic acid encapsulation efficiency and reduced leakage from the capsules as compared to those made with alginate alone, they showed higher folic acid retention after freeze drying and storage[32].

In relation to cosmetics, using citronellal as a model compound, pectin gel formulations were evaluated for controlled fragrance release by kinetic and static methods. These formulations showed a prolonged duration of fragrance release and limitation of fragrance adsorption to the receptor skin layers. The increase in pectin concentrations suppressed the fragrance release by a diffusion mechanism, thereby proving that pectin/calcium microparticles are promising materials for controlled fragrance release[33].

\subsection{Inulin}

Inulin (Fig. 20) consists of a mixture of oligomers and polymers that belong to the group of gluco-fructans and occur in plants such as garlic, onion, artichoke and chicory.

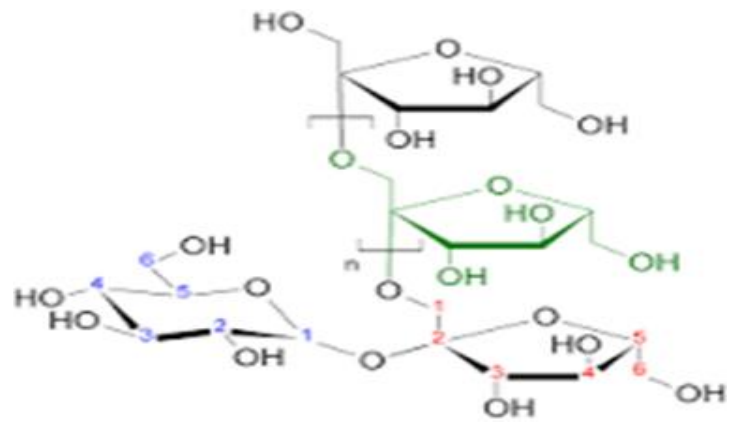

Figure 20 Chemical structure of Inulin 
The inulin molecules contain from two to more than 60 fructose molecules linked by $\beta-2,1$ - bonds. Inulin is resistant to digestion in the upper gastrointestinal tract, but is degraded by colonic microflora. Inulin with a high degree of polymerisation was used to prepare biodegradable colon-specific films in combination with Eudragitß RS that could withstand break down by the gastric and intestinal fluids [34]. It was shown in another study where different Eudragits $\AA$ were formulated into films with inulin that when a combination of Eudragit@ RS and Eudragitß RL was mixed with inulin it exhibited better swelling and permeation properties in colonic medium rather than other gastrointestinal media. Methylated inulin hydrogels were developed as colon-specific drug delivery systems and investigated for water uptake and swelling. The hydrogels exhibited a relatively high rate of water uptake and anomalous dynamic swelling behaviour Inulin derivatised with methacrylic anhydride and succinic anhydride produced a pH sensitive hydrogel by UV irradiation that exhibited a reduced swelling and low chemical degradation in acidic medium, but it had a good swelling and degradation in simulated intestinal fluid in the presence of its specific enzyme, inulinase [35].

\subsection{Carrageenans}

Carrageenans (Fig. 21) is the generic name for a family of high molecular weight sulphated polysaccharides obtained from certain species of red seaweeds belonging to the class Rhodophyceae, especially Chondrus crispus, Euchema spp, Gigartina stellata and Iridaea spp. Carrageenan extracted from seaweed is not assimilated by the human body and provides only bulk but no nutrition.

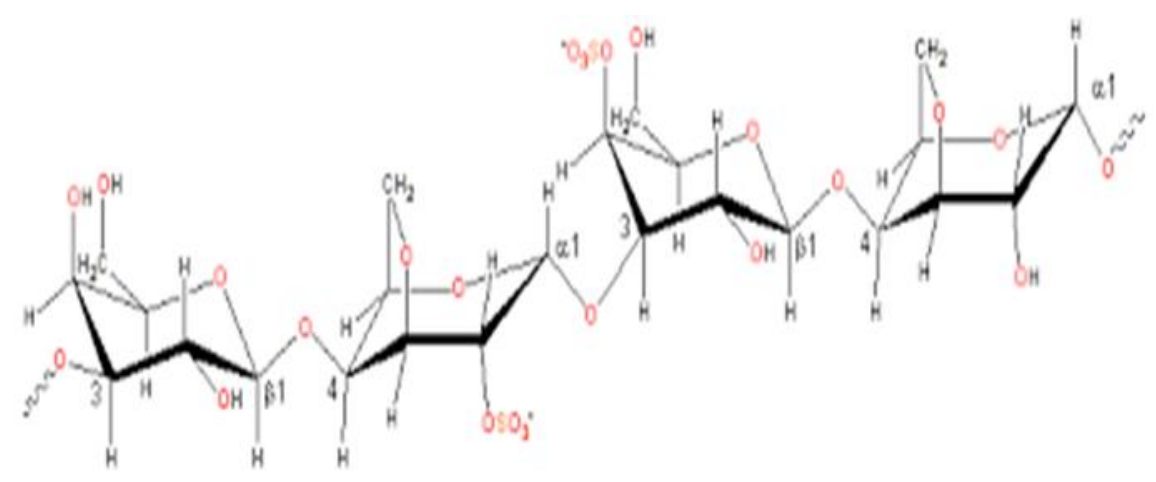

Figure 21 Chemical structure of Carrageenan

There are three basic types of carrageenan kappa $(\kappa)$, iota $(l)$ and lambda $(\lambda)$. The $\lambda$-type carrageenan results in viscous solutions but is non-gelling, while the ktype carrageenan forms a brittle gel. The ı-type carrageenan produces elastic gels. A study where the compaction ability of two $\kappa$-carrageenans (Gelcarin ${ }^{\circ}$ GP-812 NF and GP-911 NF) and one tcarrageenan (Gelcarin ${ }^{\circ}$ GP-379 NF) was investigated showed that these carrageenans are able to form strong compacts with a high elastic recovery. It was finally concluded from the results that the carrageenans investigated were suitable tableting excipients for the manufacturing of controlled-release tablets. In another study, matrices made of $\mathrm{t}$ carrageenan and $\lambda$-carrageenan sustained the release of three different model drugs and showed release profiles that approached zero order kinetics. It was found that factors such as tablet diameter, drug to carrageenan ratio and ionic strength of the dissolution medium may play a role in the release of drug from these matrices. Hydrogel beads were prepared from a mixture of cross-linked $\kappa$-carrageenan with potassium and cross-linked alginate with calcium and they exhibited a smoother surface morphology than that of the one-polysaccharide network beads. The carrageenan parts of the hydrogel pronouncedly enhanced the thermostability of the polymeric network. These beads were introduced as novel carriers for controlled drug delivery systems [36].

\subsection{Alginates}

Alginates (Fig. 22) are natural polysaccharide polymers isolated from the brown sea weed (Phaeophyceae). Alginic acid can be converted into its salts, of which sodium alginate is the major form currently used. 


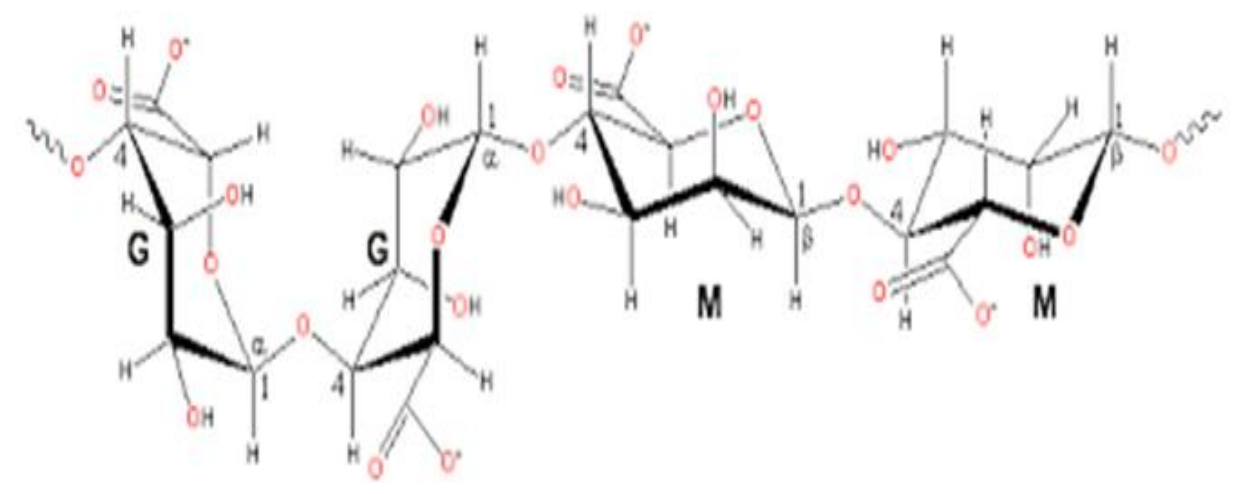

Figure 22 Chemical structure of alginate

A linear polymer consisting of D-mannuronic acid and L-guluronic acid residues arranged in blocks in the polymer chain. Alginates offer various applications in drug delivery, such as in matrix type alginate gel beads, in liposomes, in modulating gastrointestinal transit time, for local applications and to deliver the bio molecules in tissue engineering applications.

Bioadhesive sodium alginate microspheres of metoprolol tartrate for intranasal systemic delivery were prepared to avoid the first-pass effect, as an alternative therapy to injection, and to obtain improved therapeutic efficacy in the treatment of hypertension and angina pectoris. The microspheres were prepared using emulsification-cross linking method. In vivo studies indicated significantly improved therapeutic efficacy of metoprolol from microspheres, with sustained and controlled inhibition of isoprenaline-induced tachycardia as compared with oral and nasal administration of drug solution[37].

A new insert, basically consisting of alginates with different hydroxyethylcellulose content was developed to maintain a constant drug level over a certain period in the eye. This study showed good tolerance of the new calcium-alginateinsert applied to the ocular surface for controlled drug release[38] .In order to achieve 24 h release profile of water soluble drugs, sodium alginate formulation matrices containing xanthan gum or zinc acetate or both were investigated.

In a comparative study, alginate formulation appeared to be better than the polylactide-co-glycolide (PLG) formulation in improving the bioavailability of two clinically important antifungal drugs-clotrimazole and econazole. The nanoparticles were prepared by the emulsion-solvent-evaporation technique in case of PLG and by the cation-induced controlled gelification in case of alginate[39].

\subsection{Starches}

It is the principal form of carbohydrate reserve in green plants and especially present in seeds and underground organs. Starch (Fig. 23) occurs in the form of granules (starch grains), the shape and size of which are characteristic of the species, as is also the ratio of the content of the principal constituents, amylose and amylopectin.

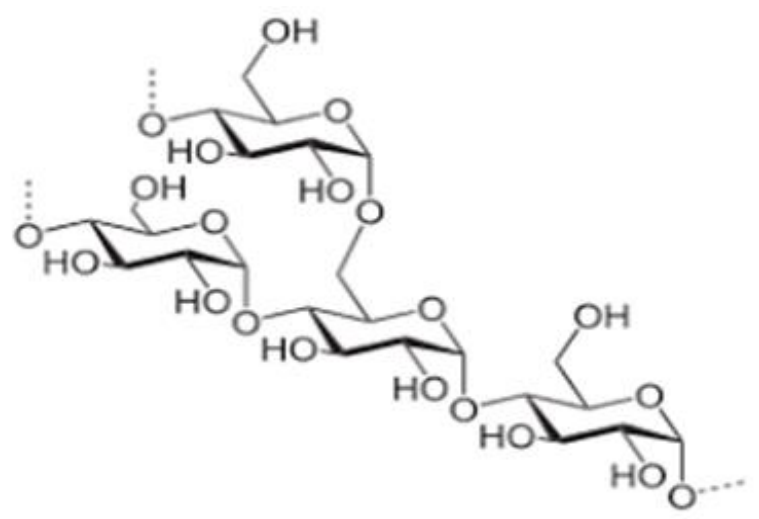

Figure 23 Chemical structure of starch 
A number of starches are recognized for pharmaceutical use. These include maize (Zea mays), rice (Oryza sativa), wheat (Triticum aestivum) and potato (Solanum tuberosum).

Modified starch was tested for general applicability of a new pregelatinized starch product in directly compressible controlled-release matrix systems. It was prepared by enzymatic degradation of potato starch followed by precipitation (retrogradation), filtration and washing with ethanol. The advantages of the material include ease of tablet preparation, the potential of a constant release rate (zero-order) for an extended period of time and its ability to incorporate high percentages of drugs with different physicochemical properties. Release rates from retrograded pregelatinized starch tablets can be enhanced or decreased to the desired profile by different parameters like geometries of the tablet, compaction force and the incorporation of additional excipients.

To deliver proteins or peptidic drugs orally, microcapsules containing a protein and a proteinase inhibitor were prepared. Starch/bovine serum albumin mixed-walled microcapsules were prepared using interfacial cross-linking with terephthaloyl chloride. The microcapsules were loaded with native or amino-protected aprotinin by incorporating protease inhibitors in the aqueous phase during the cross-linking process. The protective effect of microcapsules with aprotinin for bovine serum albumin was revealed in vitro[40].

The average degree of acetyl substitution (DS) per glucose residue in the starch was either 1.9 (SA DS 1.9) or 2.6 (SA DS 2.6). Timolol, calcein and BSA were used as model drugs. This study demonstrated the achievement of slow release of different molecular weight model drugs from the SA mps and films as compared to fast release from the native starch preparations[41].

\subsection{Gums}

Gums are translucent and amorphous substances produced by the plants. Usually pathological products, gums are produced when the plant is growing under unfavorable conditions or when injured. Gums are plant hydrocolloids and may be anionic or non ionic polysaccharides. On hydrolysis gums yield sugar and salts of uronic acid.

\subsubsection{Guar gum}

Guar gum (Fig. 24) derived from the seeds of cyamopsis tetragonolobus (Family Leguminosae) is a naturally occurring galactomannan polysaccharide. It is made up of a linear chain of $\beta$-D-mannopyranose joined by $\beta$-(1-4) linkage with $\alpha$ D-galactopyranosyl units attached by 1,6- links in the ratio of $1: 2^{2}$.

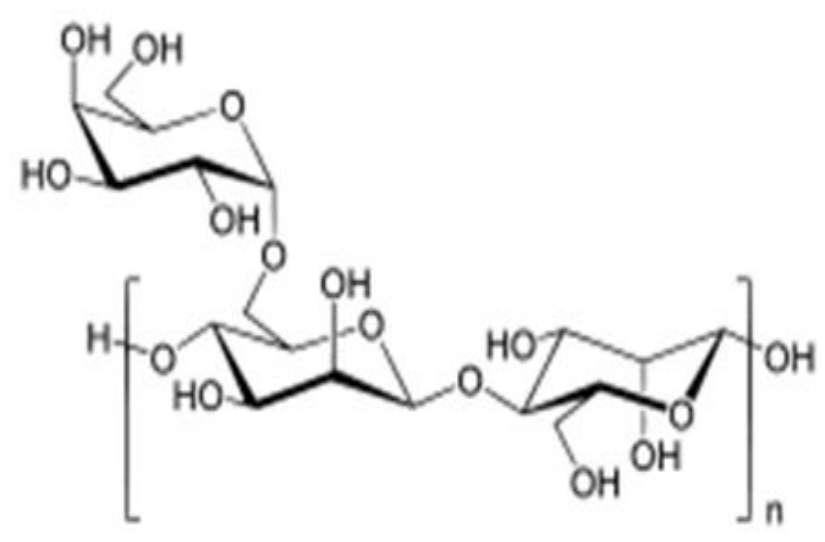

Figure 24 Chemical structure of guar gum

Guar gum is used in colon-delivery systems due to its drug release retarding property and susceptibility to microbial degradation in the large intestine. Core tablets containing 5-aminosalisylic acid (5-ASA) were prepared by wet granulation with starch paste and were compression coated with coating formulations containing different quantities of guar gum The study confirmed that selective delivery of 5-ASA to the colon can be achieved using guar gum as a carrier in the form of a compression coating over the drug core[42].

Further, guar gum-based matrix tablets of rofecoxib were prepared for their intended use in the chemoprevention of colorectal cancer. In vivo studies showed delayed $\mathrm{T}_{\max }$, prolonged absorption time and decreased $\mathrm{C}_{\max }$ indicating that rofecoxib was not released significantly in stomach and small intestine, but was delivered to colon resulting in a slow absorption of the drug and making it available for local action in human colon[43]. 
In an attempt to design oral controlled drug delivery systems for highly water-soluble drugs using guar gum as a carrier in the form of three-layer matrix tablets, trimetazidine dihydrochloride was chosen as a model drug because of its high water solubility. Both matrix tablets as well as three layer matrix tablets were prepared and evaluated. The three-layer guar gum matrix tablet provided the required release rate on par with the theoretical release rate for guar gum formulations meant for twice daily administration.

The results indicated that guar gum, in the form of three-layer matrix tablets, is a potential carrier in the design of oral controlled drug delivery systems for highly water-soluble drugs such as trimetazidine dihydrochloride. The same study was carried out by using metoprolol tartrate a model drug with high solubility. The results indicated that guar gum, in the form of three-layer matrix tablets, is a potential carrier in the design of oral controlled drug delivery systems for highly water-soluble drugs such as metoprolol tartrate.

Another water soluble drug, diltiazem $\mathrm{HCl}$ has given controlled release comparable with marketed sustained release diltiazem $\mathrm{HCl}$ tablets (D-SR tablets), which are prepared in the form of matrix tablets with guar gum using the wet granulation technique[44].

\subsubsection{Gum acacia}

Gum acacia or gum Arabic (Fig. 25) is the dried gummy exudate obtained from the stem and branches of Acacia senegal (Linne) Willdenow and other related species of acacia (Family Leguminosae). The gum has been recognized as an acidic polysaccharide containing D-galactose, L-arabinose, L-rhamnose, and D-glucuronic acid.

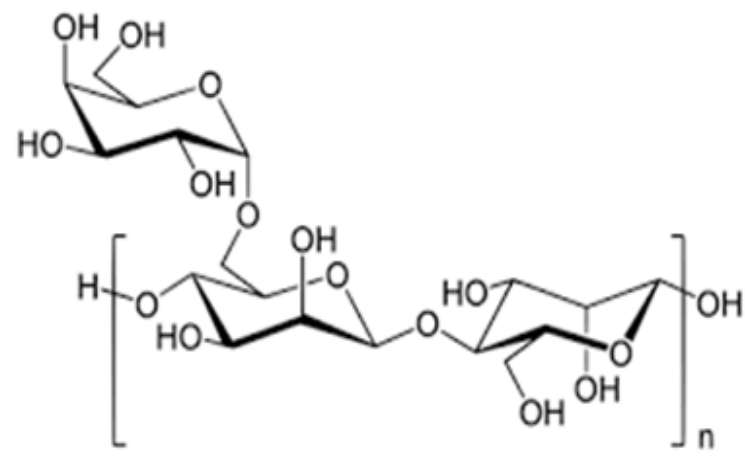

Figure 25 Chemical structure of gum acacia

Acacia is mainly used in oral and topical pharmaceutical formulations as a suspending and emulsifying agent, often in combination with tragacanth. It is also used in the preparation of pastilles and lozenges and as a tablet binder.

Sustained release of ferrous sulfate was achieved for $7 \mathrm{~h}$ by preparing gum arabic pellets. Release was further sustained for more than $12 \mathrm{~h}$ by coating the pellets with polyvinyl acetate and ethylene vinyl acetate, respectively. An increase in the amount of gum arabic in the pellets decreased the rate of release due to the gelling property of gum arabic. The gel layer acts as a barrier and retards the rate of diffusion of $\mathrm{FeSO}_{4}$ through the pellet[45].

Gum arabic was used as an osmotic, suspending and expanding agent in the preparation of a monolithic osmotic tablet system (MOTS) with two orifices on both side surfaces. Water-insoluble naproxen was selected as the model drug. The optimal MOTS were found to be able to deliver naproxen at a rate of approximately zero order up to $12 \mathrm{~h}$ in pH 6.8 . Cumulative release at $12 \mathrm{~h}$ is $81 \%$, and is independent of environment media and stirring rate. Therefore, these MOTS can be used in the oral drug-controlled delivery field, especially for water-insoluble drugs.

\subsubsection{Karaya gum}

Karaya gum (Fig. 26) is obtained from Sterculia urens (Family sterculiaceae) is a partially acetylated polymer of galactose, rhamnose, and glucuronic acid. 


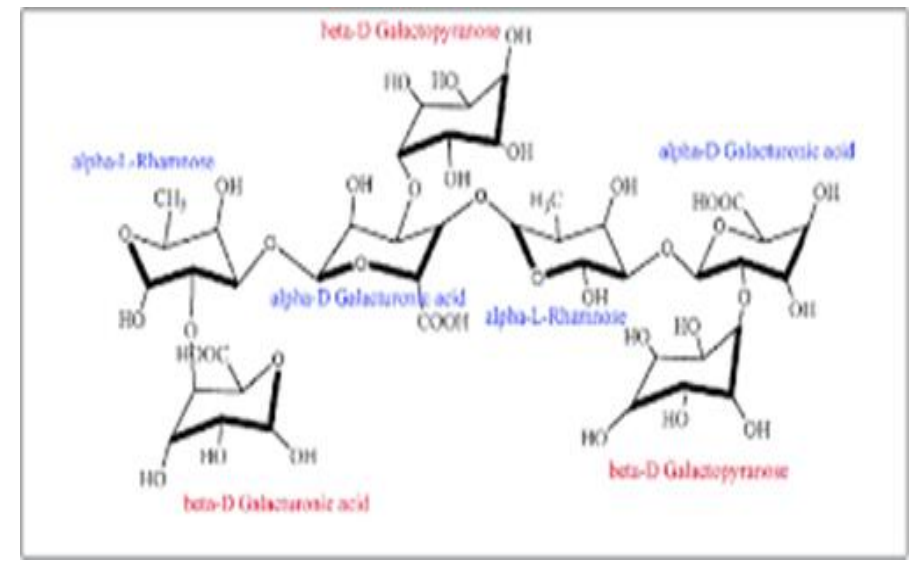

Figure 26 Chemical structure of karaya gum

Swellable hydrophilic natural gums like xanthan gum and karaya gum were used as release-controlling agents in producing directly compressed matrices. Caffeine and diclofenac sodium, which are having different solubilities in aqueous medium were selected as model drugs. Gum erosion, hydration and drug release studies were carried out using a dissolution apparatus (basket method) at two agitation speeds. In case of xanthan gum neither agitation speed nor drug solubility had any significant effect on water uptake, but matrices with the lower proportion of gum produced a lesser degree of hydration. In contrast, karaya gum displayed a much lower hydration capacity and a higher rate of erosion, both markedly affected by agitation speed. Hence it was concluded that drug release from xanthan and karaya gum matrices depended on agitation speed, solubility and proportion of drug. Both xanthan and karaya gums produced near zero order drug release with the erosion mechanism playing a dominant role, especially in karaya gum matrices[46].

\subsubsection{Xanthan gum}

Xanthan gum (Fig. 27) is a high molecular weight extra cellular polysaccharide produced by the fermentation of the gram-negative bacterium Xanthomonas campestris. The primary structure of this naturally produced cellulose derivative contains a cellulosic backbone ( $\beta$-D-glucose residues) and a trisaccharide side chain of $\beta$-D-mannose- $\beta$-Dglucuronic acid- $\alpha$-D-mannose attached with alternate glucose residues of the main chain. The terminal D-mannose residue may carry a pyruvate function, the distribution of which is dependent on the bacterial strain and the fermentation conditions. The non-terminal D-mannose unit in the side chain contains an acetyl function. The anionic character of this polymer is due to the presence of both glucuronic acid and pyruvic acid groups in the side chain.

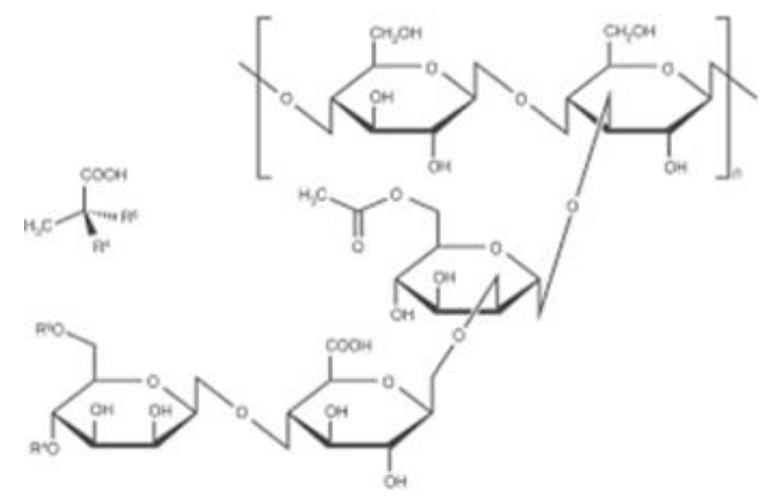

Figure 27 Chemical structure of xanthan gum

In one of the trials, xanthan gum showed a higher ability to retard the drug release than synthetic hydroxyl propylmethylcellulose. Xanthan gum and hydroxyl propylmethylcellulose were used as hydrophilic matrixing agents for preparing modified release tablets of diltiazem $\mathrm{HCl}$. The amount of hydroxyl propylmethylcellulose and xanthan gum exhibited significant effect on drug release from the tablets prepared by direct compression technique. It was concluded that by using a suitable blend of hydroxyl propylmethylcellulose and xanthan gum desired modified drug release could be achieved. 
Compaction and compression properties of xanthan gum pellets were evaluated and drug release from tablets made of pellets was characterized. Two types of pellets were prepared by extrusion-spheronisation. Formulations included xanthan gum, at $16 \%(\mathrm{w} / \mathrm{w})$ and diclofenac sodium or ibuprofen, at $10 \%(\mathrm{w} / \mathrm{w})$ among other excipients. Physical properties of pellets and tablets were analysed. Laser profilometry analysis and scanning electron microscopy of the upper surface and the surface of fracture of tablets revealed that particles remained as coherent individual units after compression process. Pellets showed close compressibility degrees (49.9\% for pellets comprising diclofenac sodium and $48.5 \%$ for pellets comprising ibuprofen). The release of the model drug from both type of tablets revealed different behaviors. Tablets made of pellets comprising ibuprofen released the model drug in a bimodal fashion and the release behavior was characterized as Case II transport mechanism (release exponent of 0.93). On the other hand, the release behavior of diclofenac sodium from tablets made of pellets was anomalous (release exponent of 0.70). For the latter case, drug diffusion and erosion were competing mechanisms of drug release[47].

By utilizing retention properties of xanthan gum and releasing properties of galactomannan, desire release profile was achieved in delivery of theophylline. Hydrophilic galactomannan is obtained from the seeds of the Brazilian tree Mimosa scabrella (Family Leguminosae). The matrices made alone with xanthan gum (X) showed higher drug retention for all concentrations, compared with galactomannan (G) matrices that released the drug too fast. The matrices prepared by combination of both gums were able to produce near zero-order drug release. The XG (conc. 8\%) tablets provided the required release rate (about $90 \%$ at the end of $8 \mathrm{~h}$ ), with zero-order release kinetics.

\subsubsection{Tragacanth gum}

It is an anionic polysaccharide produced by drying exudates from the stems and branches of Astrag-alus species with different compositions. The chemical structure of gum tragacanth (Fig. 28) is defined as a complex and highly branched polysaccharide consisting of small proportions of protein.

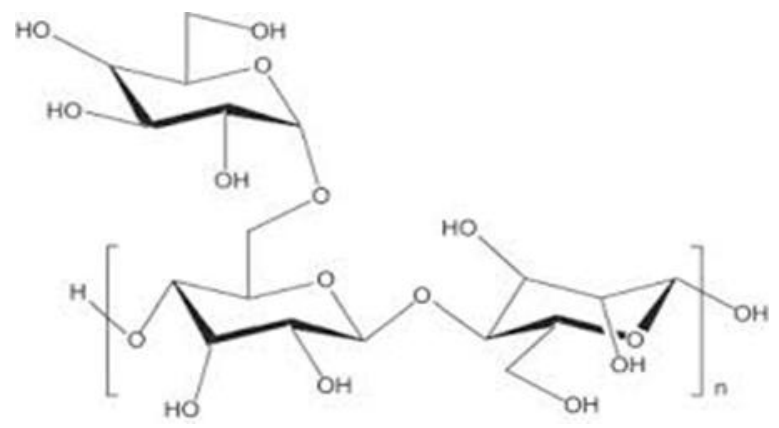

Figure 28 Chemical structure of gum tragacanth

This gum is obtained from the branches of Astragalus gummifer, (family: Leguminosae). Tragacanth when used as the carrier in the formulation of 1- and 3-layer matrices produced satisfactory release prolongation either alone or in combination with other polymers[48].

\subsection{Volatile Oils}

Volatile oils are generally mixtures of hydrocarbons and oxygenated compounds derived from these hydrocarbons. Many oils are terpenoid in origin; some of them are aromatic derivatives mixed with terpenes (e.g. cinnamon and clove). A few compounds (e.g. thymol and carvacrol) although aromatic in structure, are terpenoid in origin.

\subsubsection{Menthol}

Menthol (Fig. 29) is an organic compound made synthetically or obtained from the oils of corn mint, peppermint, or other mints. It is a waxy, crystalline substance, clear or white in color, which is solid at room temperature and melts slightly above. 


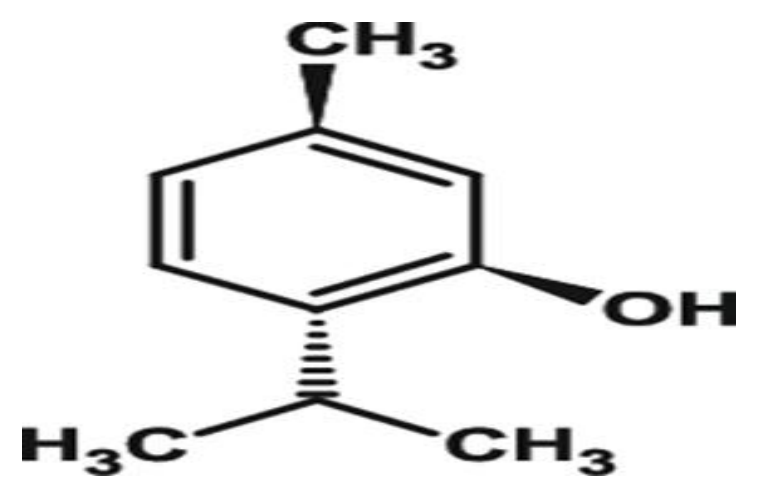

Figure 29 Chemical structure of menthol

Menthol is obtained by steam distillation of the flowering tops of Mentha piperita (family Labiatae). A membranemoderated transdermal therapeutic system (TTS) of nimodipine using $2 \% \mathrm{w} / \mathrm{w}$ hydroxyl propylmethylcellulose (HPMC) gel as a reservoir system containing menthol as penetration enhancer and $60 \% \mathrm{v} / \mathrm{v}$ ethanol-water as solvent system was prepared. The in vivo evaluation of nimodipine TTS patch was carried out to find the ability of the fabricated menthol-based TTS patch in providing the predetermined plasma concentration of the drug in human volunteers. The results showed that the menthol-based TTS patch of nimodipine provided steady plasma concentration of the drug with minimal fluctuations with improved bioavailability in comparison with the immediate release tablet dosage form.

Menthol was tested for improving the bioavailability of poorly water-soluble ibuprofen in the rectum with poloxamer. The effects of menthol and poloxamer 188 on the aqueous solubility of ibuprofen were investigated. The poloxamer gel with poloxamer 188 and menthol was found to be a more effective rectal dosage form for ibuprofen[49]. Terpenes such as menthol, cineole and propylene glycol (PG) were tested as chemical enhancers to improve the skin penetration of propranolol. Release and skin permeation kinetics of propranolol from film preparations were examined in in vitro studies using a Franz-type diffusion cell. In vitro skin permeation studies showed that cineole was the most promising enhancer among the enhancers examined.

\subsubsection{Caraway}

Caraway fruit consists of the dried, ripe fruits of Carum carvi (Family Umbelliferae). The volatile oil consists of the ketone carvone (Fig. 30) and the terpene limonene.

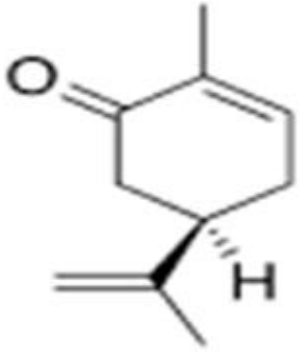

(R)

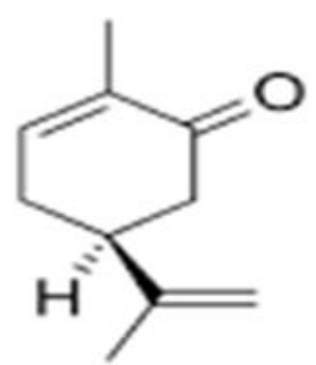

(S)

Figure 30 Chemical structure of carvone

In another attempt, a limonene-based transdermal therapeutic system (TTS) was prepared to study its ability to provide the desired steady-state plasma concentration of nicorandil in human volunteers. It was concluded that the limonenebased TTS of nicorandil provided the desired plasma concentration of the drug for the predetermined period of time with minimal fluctuations and improved bioavailability [50]. .

In a similar manner a carvone based and nerodilol based transdermal therapeutic systems were prepared using nicorandil as a model drug. It was concluded that both TTS of nicorandil provided the desired in vivo controlled-release profile of the drug for the predetermined period of time. 


\section{Conclusion}

Today the stress is on patient compliance and to achieve this objective there is a spurt in the development of NDDS. Natural gums are promising biodegradable polymeric materials. Many studies have been carried out in fields, including food technology and pharmaceuticals using gums. Clearly gums have many advantages over synthetic materials. Majority of investigations on natural polymers in drug delivery systems centre around polysaccharides. Natural gums can also be modified to have tailor-made products for drug delivery systems and thus can compete with the synthetic excipients available in the market. Various applications of gums have been established in the field of pharmaceuticals. However, there is a need to develop other natural sources as well as with modifying existing natural materials for the formulation of novel drug-delivery systems, biotechnological applications and other delivery systems. As these gums and mucilages are non-toxic, freely available, and less expensive compared to their synthetic counterparts. They have a major role to play in pharmaceutical industry. Therefore, in the years to come, there is going to be continued interest in the natural excipients to have better materials for drug delivery systems.

\section{Compliance with ethical standards}

\section{Acknowledgments}

All the authors are highly thankful to their respective management for their encouragement for preparing new searching/findings.

\section{Disclosure of conflict of interest}

The authors declare that there is no conflict of interests regarding the publication of this paper.

\section{References}

[1] USP Subcommittee on excipients. Pharm Forum. (1992). 18, 4387.

[2] Sinha VR and Rachna K. (2001). Polysaccharides in colon specific drug delivery. International Journal of Pharmaceutics, 224(1-2), 19-38.

[3] Khanna M, Dwivedi AK and Singh S. (1997). Polyose from seeds of Tamarindus indica of unique property and immense pharmaceutical use. Trends in Carbohydrate Chemistry, 4, 79-81.

[4] Satle A and Agrawal S. (2012). Solubility enhancement potential of tamarind seed polysaccharide as pharmaceutical excipient. International Journal of Pharmaceutical \& Biological Archives, 3(3), 456-459.

[5] Mishra MU and Khandare JN. (2011). Evaluation of tamarind seed polysaccharide as a biodegradable carrier for colon specific drug delivery. International Journal of Pharmacy and Pharmaceutical Sciences, 3(1), $139-142$.

[6] Beneke CE, Viljoen AM and Hamman JH. (2009). Polymeric plant-derived excipients in drug delivery. Molecules, 14(7), 2602-2620.

[8] Naveen G, Naik VV, Kumar GD and Samifer S. (2013). Effect of mucilage of Abelmoschus esculentus as tablet binder in diclofenac sodium matrix tablets. International Journal of Pharmaceutical and Chemical Sciences, 2(3), 1320-1323.

[9] Kumar R, Patil S, Patil MB, Patil SR and Paschapur MS. (2009). Isolation and evaluation of disintegrant properties of fenugreek seed mucilage. International Journal of PharmTech Research, 1(4), 982-996.

[10] Zafar N, Neeharika V and Laxmi PK. (2014). Formulation and evaluation of sildenafil citrate fast dissolving tablets using fenugreek seed mucilage. International Journal of Research in Ayurveda and Pharmacy, 5(3), $352-358$.

[11] Malvia R, Shrivastava P, Bansal M and Sharma PK. (2010). Mangos peel pectin as a superdisintegrating agent. Journal of Scientific and Industrial Research, 2(1), 688-690.

[12] Krishnaiah YS, Chandrasekhar DV, Rama B, Jayaram B, Satyanarayana V and Al-Saidan SM. (2005). A limonenebased transdermal therapeutic system (TTS) was prepared to study its ability to provide the desired steady-state plasma concentration of nicorandil in human volunteers. Skin Pharmcolology and Physiology, 18(6), 263-272. 
[13] Morkhade DM and Joshi SB. (2007). Evaluation of gum damar as a novel microencapsulating material for ibuprofen and diltiazem hydrochloride. Indian Journal of Pharmaceutical Sciences, 69(2), 263-269.

[14] Fulzele SV, Satturwar PM and Dorle AK. (2002). Polymerized rosin: novel film forming polymer for drug delivery. International Journal of Pharmceutics, 249(1-2), 175-184.

[15] Satturwar PM, Fulzele SV and Dorle AK. (2003). Biodegradation and in vivo biocompatibility of rosin: a natural film-forming polymer. AAPS PharmSciTech, 4(4), 1-6.

[16] Odeku OA and Fell JT. (2005). In-vitro evaluation of khaya and albizia gums as compression coatings for drug targeting to the colon. Journal of Pharmacy and Pharmacology, 57(2), 163-168.

[17] Üner M and Altinkurt T. (2004). Evaluation of honey locust (Gleditsia triacanthos Linn.) gum as sustaining material in tablet dosage forms. Il Farmaco, 59(7), 567-573.

[18] Lima RDN, Lima JR, De Salis CR and Moreira RA. (2002). Cashew-tree (Anacardium occidentale L.) exudate gum: a novel bio-ligand tool. Biotechnology and Applied Biochemistry, 35(1), 45-53.

[19] Gangurde AB, Malode SS and Bhambar RS. (2008). Preliminary evaluation of neem gum as tablet binder. Indian Journal of Pharmaceutical Education and Research, 42(4), 344-347.

[20] Choi S and Chung MH. (2003). A review on the relationship between Aloe vera components and their biologic effects. Seminars in Integrative Medicine, 1(1), 53-62.

[21] Ahad HA, Kumar CS, Kumar AB, Reddy AB, Shekar CA, Ravindra BV and Venkatnath LS. (2010). Development and in vitro evaluation of glibenclamide Aloe barbadensis miller leaves mucilage controlled release matrix tablets. International Journal of PharmTech Research, 2(2), 1018-1021.

[22] Panda D, Choudhury NSK, Yedukondalu M, Si S and Gupta R. (2008). Evaluation of gum of Moringa oleifera as a binder and release retardant in tablet formulation. Indian Journal of Pharmaceutical Sciences, 70(5), 614-618.

[23] Patel BV and Patel D. (2011). Study of disintegrant property of Moringa oleifera gum and its comparison with other superdisintegrants. International Journal of ChemTech Research, 3(3), 1119-1124, 2011.

[24] Ngwuluka NC, Idiakhoa BA, Nep EI, Ogaji I and Okafor IS. (2010). Formulation and evaluation of paracetamol tablets manufactured using the dried fruit of Phoenix dactylifera Linn as an excipient. Research in Pharmaceutical Biotechnology, 2(3), 25-32.

[25] Soni PL and Pal R. (1996). Industrial gum from Cassia tora seeds, Trends in Carbohydrate Chemistry. 2, 33-44.

[26] Singh S, Bothara DSB and Singh S. (2010). Pharmaceutical characterization of Cassia tora of seed mucilage in tablet formulations. Scholars Research Library, 2(5), 54-61.

[27] Mann AS, Jain NK and Kharya MD. (2007). Evaluation of the suspending properties of Cassia tora mucilage on sulphadimidine suspension. Asian Journal of Experimental Sciences, 21(1), 63-67.

[28] Singh K, Kumar A, Langyan N and Ahuja M. (2009). Evaluation of Mimosa pudica seed mucilage as sustainedrelease excipient. AAPS PharmSciTech, 10(4), 1121-1127.

[29] Bamiro OA, Sinha VR, Kumar R and Odeku OA. (2010). Characterization and evaluation of Terminalia randii gum as a binder in carvedilol tablet formulation. Acta Pharmaceutica Sciencia, 52(3), 254-262.

[30] Sheth NS, Shah NV and Shah NC. (2010). Extraction of mucilage from Ocimum americanum linn and its role as disintegrant in tablets formulation. Journal of Global Pharma Technology, 2(12), 26-31.

[31] Giunchedi P, Conte U, Chetoni P and Saettone MF. (1999). Pectin microspheres as ophthalmic carriers for piroxicam: Evaluation in vitro and in vivo in albino rabbits. European Journal of Pharmaceutical Sciences, 9(1), $1-7$.

[32] Cheng K and Lim LY. (2004). Insulin-loaded calcium pectinate nanoparticles: Effects of pectin molecular weight and formulation pH. Drug Development and Industrial Pharmacy, 30(4), 359-367.

[33] Madziva H, Kailasapathy K and Phillips M. (2005). Alginate-pectin microcapsules as a potential for folic acid delivery in foods. Journal of Microencapsulation, 22(4), 343-351.

[34] Liu L, Chen G, Fishman ML and Hicks KB. (2005). Pectin gel vehicles for controlled fragrance delivery. Drug Delivery, 12(3), 149-157.

[35] Vervoort L and Kinget R. (1996). In vitro degradation by colonic bacteria of inulinHP incorporated in Eudragit RS films. International Journal of Pharmceutics, 129(1-2), 185-190. 
[36] Castelli F, Sarpietro MG, Micieli D, Ottim S, Pitarresi G, Tripodo G, Carlisi B and Giammona G.(2008). Differential scanning calorimetry study on drug release from an inulin-based hydrogel and its interaction with a biomembrane model: pH and loading effect. European Journal of Pharmaceutical Sciences 35(1-2), 76-85.

[37] Mohamadnia Z, Zohuriaan-Mehr MJ, Kabiri K, Jamshidi A and Mobedi H. (2008). Ionically crosslinked carrageenan-alginate hydrogel beads. Journal of Biomaterials Science, Polymer Edition, 19(1), 47-59.

[38] Rajinikanth PS, Sankar C and Mishra B. (2003). Sodium alginate microspheres of metoprolol tartrate for intranasal systemic delivery: Development and evaluation. Drug Delivery, 10(1), 21-28.

[39] Fuchs-Koelwel B, Koelwel C, Gopferich A, Gabler B, Wiegrebe E and Lohmann CP. (2004). Tolerance of a new calcium-alginate-insert for controlled medication therapy of the eye. Ophthalmologe, 101(5), 496-499.

[40] Pandey R, Ahmad Z, Sharma S and Khuller GK. (2005). Nano-encapsulation of azole antifungals: Potential applications to improve oral drug delivery. International Journal of Pharmaceutics, 301(1-2), 268-276.

[41] Larionova NV, Ponchel G, Duchene D and Larionova NI. (1999). Biodegradable cross-linked starch/protein microcapsules containing proteinase inhibitor for oral protein administration. International Journal of Pharmaceutics, 189(2), 171-178.

[42] Tuovinen L, Peltonen S, Liikola M, Hotakainen M, Poso A and Jarvinen K. (2004). Drug release from starch-acetate microparticles and films with and without incorporated alpha-amylase. Biomaterials, 25(18), 4355-4362.

[43] Krishnaiah YS, Satyanarayana S and Prasad YV. (1999). Studies of guar gum compression-coated 5-aminosalicylic acid tablets for colon-specific drug delivery. Drug Development and Industrial Pharmacy, 25(5), 651-657.

[44] Al-Saidan SM, Krishnaiah YS, Satyanarayana V and Rao GS. (2005). In vitro and in vivo evaluation of guar gumbased matrix tablets of rofecoxib for colonic drug delivery. Current Drug Delivery, 2(2), 155-163.

[45] Al-Saidan SM, Krishnaiah YS, Patro SS and Satyanaryana V. (2005). In vitro and in vivo evaluation of guar gum matrix tablets for oral controlled release of water-soluble diltiazem hydrochloride. AAPS PharmSciTech, 6(1), E14-E21.

[46] Batra V, Bhowmick A, Behera BK and Ray AR. (1994). Sustained release of ferrous sulfate from polymer-coated gum arabica pellets. Journal of Pharmaceutical Sciences, 83(5), 632-635.

[47] Munday DL and Cox PJ. (2000). Compressed xanthan and karaya gum matrices: Hydration, erosion and drug release mechanisms. International Journal of Pharmaceutics, 203(1-2), 179-192.

[48] Santos H, Veiga F, Pina ME and Sousa JJ. (2005). Compaction compression and drug release properties of diclofenac sodium and ibuprofen pellets comprising xanthan gum as a sustained release agent. International Journal of Pharmaceutics, 295(1-2), 15-27.

[49] Siahi MR, Barzegar-Jalali M, Monaijemzadeh F, Ghaffari F and Azarmi S. (2005). Design and evaluation of 1- and 3-layer matrices of verapamil hydrochloride for sustaining its release. AAPS PharmSciTech, 6(4), E626-E632.

[50] Yong CS, Yang CH, Rhee JD, Lee BJ, Kim DC and Kim DD. (2004). Enhanced rectal bioavailability of ibuprofen in rats by poloxamer 188 and menthol. International Journal of Pharmaceutics, 269(1), 169-176.

[51] Krishnaiah YS, Chandrasekhar DV, Rama B, Jayaram B, Satyanarayana V and Al-Saidan SM. (2005). In vivo evaluation of limonene-based transdermal therapeutic system of nicorandil in healthy human volunteers. Skin Pharmacology and Physiology, 18(6), 263-272.

\section{How to cite this article}

Mishra MK, Singh A, Patel AK, Srivastava R and Kushwaha K. (2020). Recently investigated polymeric natural gums and mucilages for various drug delivery system. World Journal of Advanced Research and Reviews, 6(1), 50-72. 